\title{
DEVELOPMENT OF A CONTINUOUS IMPROVEMENT APPROACH IN THE MANAGEMENT OF PRACTICAL PROBLEMS IN LOGISTICS AND TRANSPORT: CASE STUDY IN NUMILOG CONSTANTINE, ALGERIA
}

\author{
SAKER BESMA \& CHAIB RACHID \\ University Fréres Mentouri Constantine 1, Algeria
}

\begin{abstract}
This article describes the progress made in the development of a continuous improvement approach to managing the practical problems of logistics and transport in the Numilog-Est platform in the Constantine region of Algeria. This approach is built in agreement with those who are directly involved in the activity. Despite the benefits and services offered by these platforms, they are exposed to many types of risks and disruptions. This has a significant impact on its performance and efficiency. As a result, these companies need to manage these risks effectively, which is the goal of our research. These risks were identified from the analysis of the data and information collected on-site during the interview and the survey conducted with the administrators of this platform during our study and processed using the data processing program according to the prioritization series. Thus, it is possible to suggest the right ideas and actions to be taken. As a case study, we took the company Numilog-Est which has three logistics platforms among which those located in the city of Constantine. The latter is a company specializing in logistics and transport. It is the first of its kind in Algeria as a major player in the logistics chain.

Keywords: risk, continuous improvement, logistics and transport platform, 5M model, Pareto analysis, priority actions.
\end{abstract}

\section{INTRODUCTION}

For years, the problem of stocking and distributing goods has been a major problem for manufacturers, especially companies that do not have storage centers because of their high costs. Where the service of storage, exchange and distribution of goods depends on logistics platforms which are the real driver of the logistics system [1]. This has led to the use of transport and logistics companies due to the increasing need to store merchandise and manage deliveries interactively on long journeys across the national territory as well as to improve transport costs. However, despite the benefits gained from its services, these companies are exposed to many types of risks and disruptions that could jeopardize their work or even their sustainability. As a result, these companies need to manage the risks, to which they are exposed, objective of our research. As a case study, we took the company Numilog-Est. The latter is a company specializing in logistics and transport. It is the first of its kind in Algeria as a major player in the logistics chain. The company has three logistics platforms, among which the one located in the city of Constantine, our study zone.

The logistics platform can be defined as the place of receipt and storage of goods for a specific purpose to be reshipped in a very short time [2], it is also considered a tool for better managing time and space. Where It provides storage spaces in addition to several activities represented in the unloading and sorting of containers by destination, the loading and unloading of trucks, as well as the transport of goods [3]. Therefore, a slight performance failure can have significant consequences on operations where the slightest grain of sand in the logistics cogs can derail an entire company. As a reminder, risk can be defined as the chance of an uncertain risk, damage, loss, or other undesirable consequence that could 
compromise the objectives of the organization [4], or even reduce the efficiency and effectiveness of the latter [5]. Consequently, the range of activities related to packaging, storage and transport activities are exposed to risk and must be overcome so that the company does not miss its objectives. From now on, to overcome these risks, it is necessary to measure them; "You can't improve what you can't measure" confirms [6]. In the past, the deadlines were long and not worrying, but today they are very short. It is calculated by the day, by the hour, even by the minute. Consequently, the authors try through this work and on the proposal of the manager of the company highlight the risks that cause delays in the loading, unloading and transport process at the Constantine logistics platform because of their impact on achieving the desired objectives and, therefore, customer dissatisfaction with delivery deadlines. These problems were established from the analysis of the data and information collected on this platform during our interview and survey carried out with the managers of this platform during our study stay. This paper is organized as follows: Section 2 describes the research methodology; Section 3 identifies the categories and sources of risks causing problems for the company; and Section 4 discusses and proposes corrective approaches by which the representatives of Numilog-Est design a framework to eliminate or mitigate these risks, or even engage in a process of continuous improvement.

\section{METHODOLOGY}

This article describes the progress accomplish to develop a continuous improvement approach in the management of practical problems of logistics and transport in the NumilogEst platform in the Constantine region. This approach constructed in accordance with those who are directly implied in the activity. The quality of this work depends on the information collected about the system in several ways qualitative, semi-quantitative or quantitative [7], [8]. The envisaged approach is to use structured interviews with those in charge of the logistics and transport chain to understand the operating principle of this company and the problems associated with various on the site operations. This allows the authors to obtain real data from the field that allows the company to build a memory of the risks and develop an action plan that meets the company's expectations, while drawing on the experience gained in the event of accidents and incidents. Conclusions or even recall experience notes. It is clear from this experience and this observation that the prevailing problems in the company are the problems related to the delay in loading, unloading and transporting goods. To better understand and master these two problems a questionnaire was developed and distributed to Operations manager, QHSE Supervisor, Logistics manager and HR, This questionnaire was developed on the principle of Ishikawa making it possible to identify all the causes that have a more or less direct influence on the problems observed (Appendix), since the questionnaire technique is considered a measurable data collection tool. The next step is to represent the data which allowed the authors obtained using illustrative forms to facilitate reading and analysis, allowing us to get a clear picture of the issues raised by those responsible for transport and logistics. Two main problems were revealed, delays in loading and unloading of goods and delays in transporting goods.

\section{PRESENTATION AND ANALYSIS OF DATA}

For a better data analysis, the authors used the Ishikawa diagram $(5 \mathrm{M})$ to better understand the cause and effect. This method allows us to find the possible causes, even the root cause of the problem [9]. The first step was to highlight all the risks that cause these two problems (Figs 1 and 2).

From the first observation of Figs 1 and 2, we note that the two problems cite all risk categories (Material, Matter, Manpower, Method, Mother Nature "environment"). 


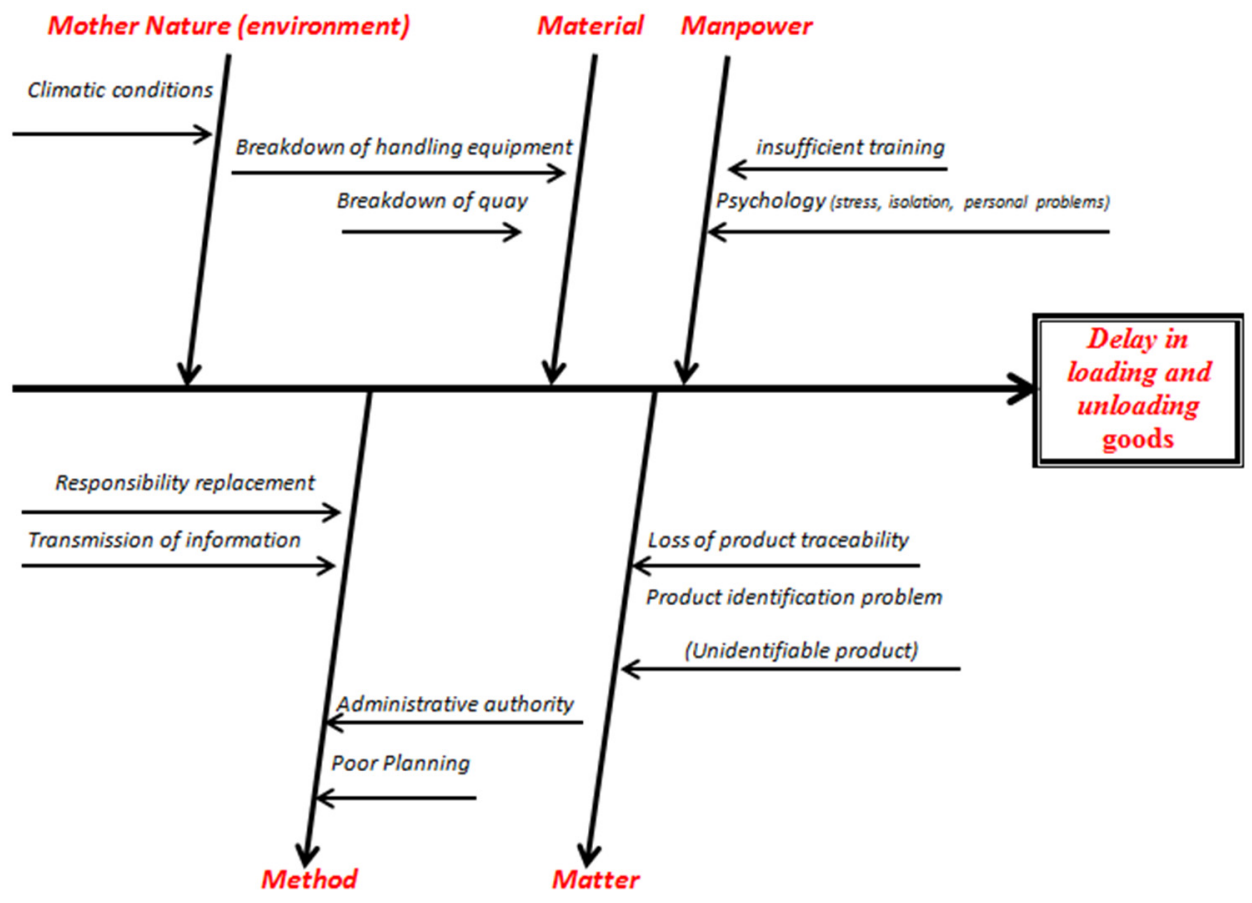

Figure 1: Cause and effect diagram of delays in loading and unloading goods.

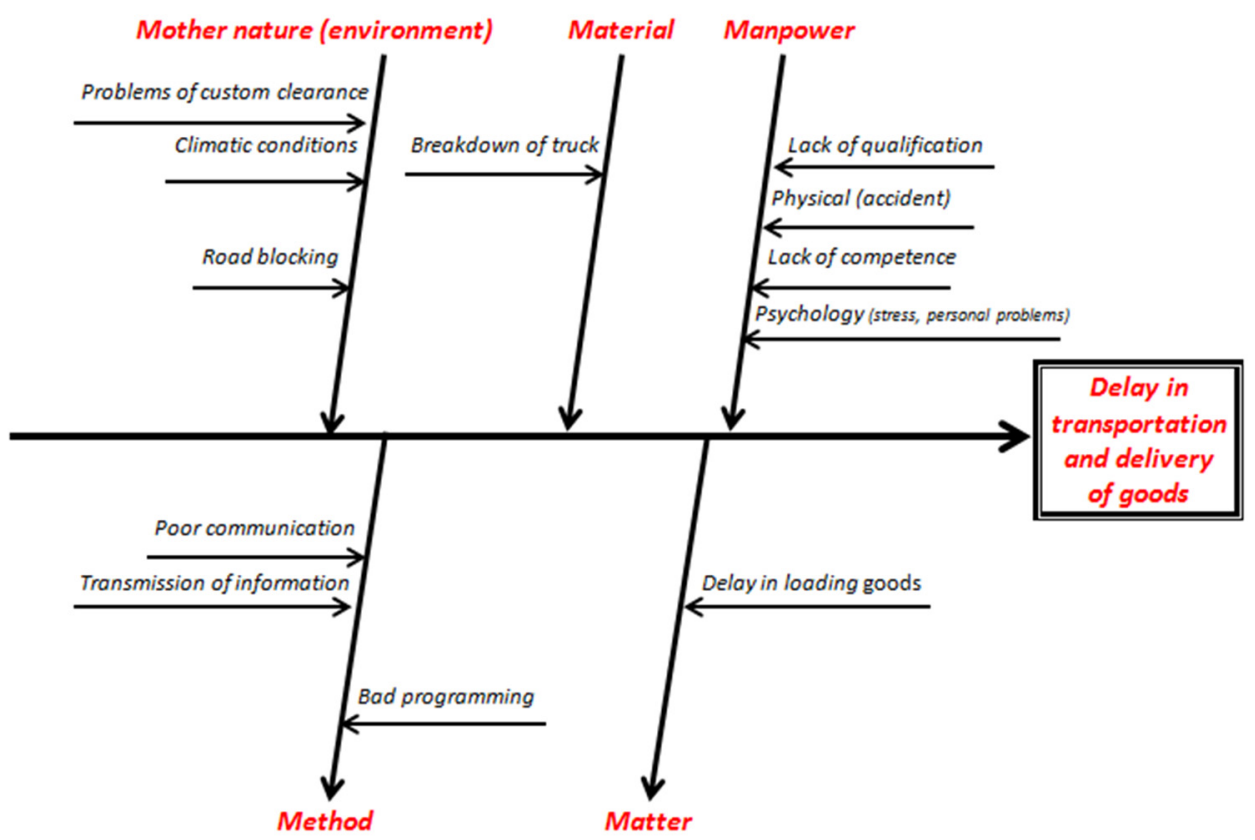

Figure 2: Cause and effect diagram of delays in transportation of goods. 
50
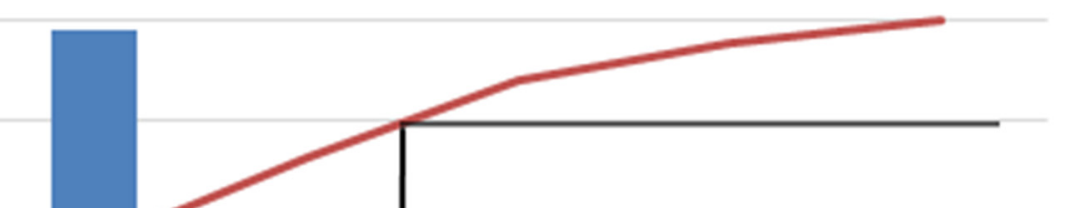

30

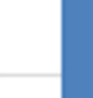

$-$

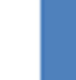

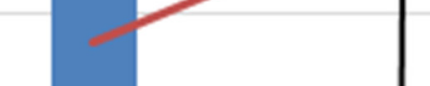

$80,00 \%$

$60,00 \%$

$40,00 \%$

$20,00 \%$

Material

\section{Method}

Matter

Manpower Mother nature

$0,00 \%$

(environment)

\section{Number of events —Cumulatived \%}

Figure 3: Presentation of the pre-prioritization of the problem of delay in loading and unloading of goods when treated by Pareto analysis.

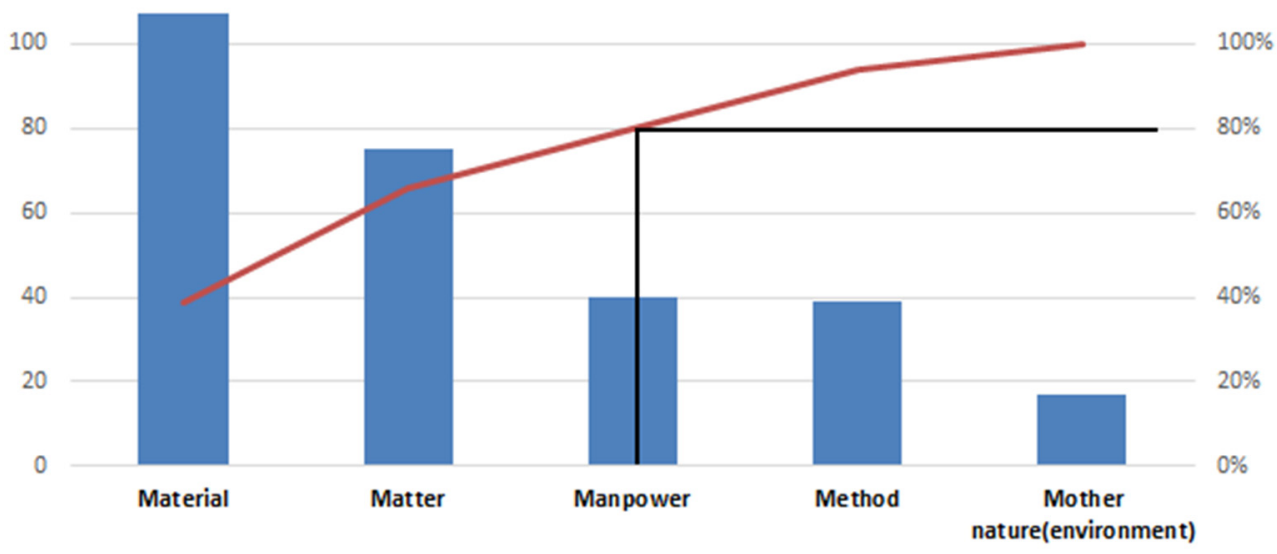

Number of events Cumulatived \%

Figure 4: Presentation of the pre-prioritization of the delay problem in transportation of goods when treated by Pareto analysis.

To best ensure the operational safety of installations, processes and operations, a company must engage in the process of continuous improvement in its management and use of its 
observations. Thus, prioritization of the actions to be taken is therefore essential for their sustainability and efficiency. The approach used for prioritizing actions is the call to the Pareto chart (20/80\%) [10], [11]. Thus, manage to prioritize the actions to be taken in the groups that have the most influence on the smooth running of the entity, or even conduct effective management guided by real field data.

The analysis of Fig. 3 shows that $80 \%$ of the risks that cause the delay in loading and unloading of goods are related, respectively, to the risks of method and material. As for the delay problem in transportation of goods, the results of Fig. 4 that $80 \%$ the risks are related to material, matter and manpower. For quality performance and to satisfy the customers at delivery time, users must pay attention to these risks.

\section{DISCUSSION AND RECOMMENDATIONS}

Following these results, the authors note that the risks raised are mainly related by method risks and material risks regarding the delay in loading and unloading the goods and, material, matter and manpower risks regarding the delay in the transportation and delivery of good. Special attention must be paid on these categories of risks, thus, to have a better and effective visualization in each category of risk, it was necessary to define another phase, the percentage of each risk in each category was used. In order to resolve these problems and engage in a continuous improvement process. The authors propose a set of tasks be assigned by priority of action. This solves many predominant risks caused the delay in loading, unloading and the transportation of goods and fulfills the needs of this system for better performance and company sustainability.

\subsection{Essential action on risks related to the delay in the loading and unloading process}

\subsubsection{For material risks}

Fig. 5 shows that breakdown of handling equipment is the dominant risk of $85.71 \%$, with a significant effect on the one hand on delays in loading, unloading and transportation of goods and customer satisfaction on the other hand, on the saturation of the storage area and associated costs. As for the breakdown of quay, it is $14.28 \%$. The latter is the main cause of the saturation of other quays leading to result in delayed activities and reduced quality of work.

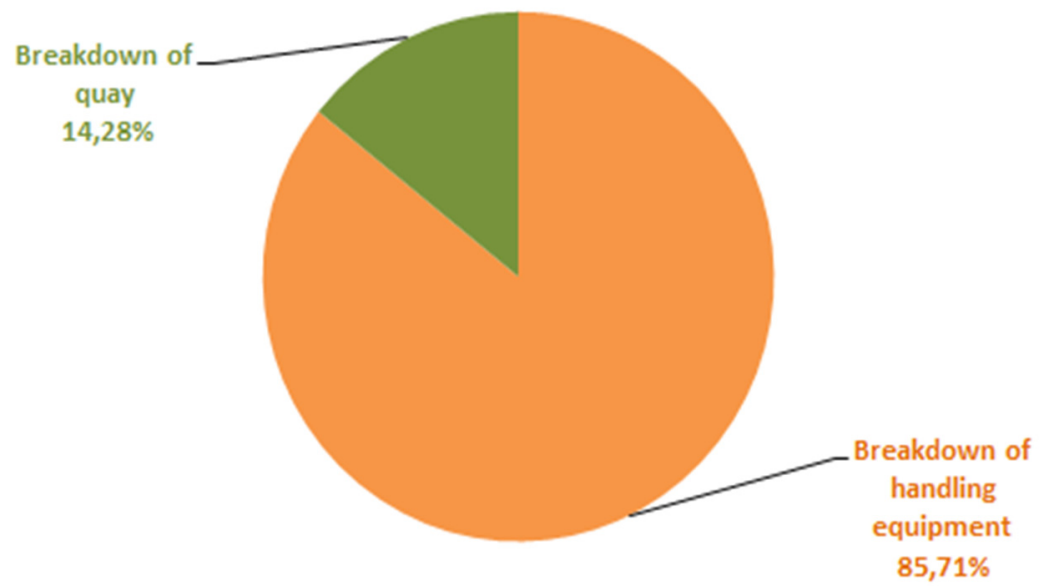

Figure 5: Representation of the material risks. 
To minimize the impact of material failures and ensure good functioning during handling activities as well as achieving profitability objectives. Periodic maintenance is essential and must be performed out daily for the equipment after each use by making a check list for equipment monitoring. This list allows the maintenance department to know all the small and large repairs and even the replacement of equipment parts.

\subsubsection{For method risks}

According to our results in Fig. 6, it is shown that $43.75 \%$ of the risk is the transmission of information, this significantly affects in the loading process and therefore the delivery performance. The effect of information transmission on a company's performance cannot be hidden, most companies has become build all their management strategies on information transfer technology. $31.25 \%$ the authors note here that this risk could lead to the impossibility of achieving the desired objective, poor planning in this platform has led to a shortage of employees compared to forecasts so better results cannot be obtained with poor planning. Administrative authority and replacement responsibility takes $12.50 \%$. Poor management by the administration and replacement of responsibility automatically leads to inconsistent and slow tasks. These method risks had a huge influence on the loading, unloading of goods and on performance and quality of their work.

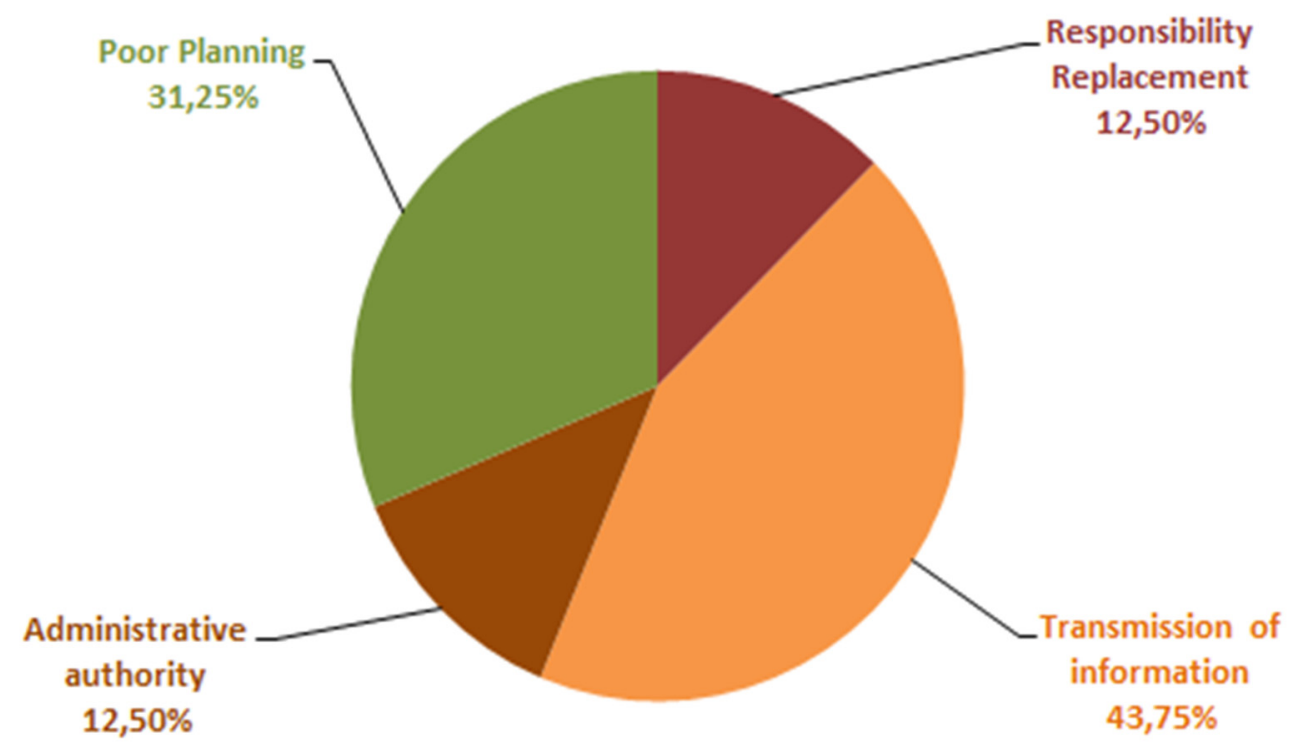

Figure 6: Representation of the method risks.

In our opinion, in order for the company to become more reliable in delivery times and more flexible in the process of loading and unloading goods, the manager must monitor and daily check the transfer and exchange of information to respond to customer requests, which positively affects the quality of work, as well a company must plan for a long time and in coordination with customers so that all changing forecast can be met without delay. Therefore, the forecast information shared with clients will enable them to determine their operational capacity. As well as focusing on cooperation between the different members of the company to coordinate the rapid response to any process. 
4.2 Essential actions on risks related to delays in the transportation of goods

4.2.1 For material risks

Fig. 7 shows that the only risk related to material is the truck breakdown. In our opinion, Aged trucks and failure to held routine maintenance increases the occurrence of these risks.

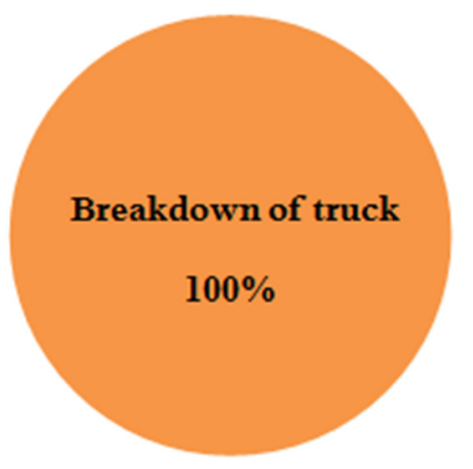

Figure 7: Representation of the material risks.

To reduce this risk, the authors suggest replacing and purchasing new trucks, also regular a maintenance service must be established at the company level; to allow for regular maintenance and create a record that includes all changes and repairs that have occurred on the truck so that it is possible to know which parts have been changed or repaired. Otherwise a contract should be entered with specialized maintenance workshops.

\subsubsection{For matter risks}

Fig. 8 shows that the only risk related with matter is the delay in loading goods. This risk is highly associated with delays in the transportation and delivery of goods. Whenever there is delay in the loading of goods, automatic there is delay in delivery of goods. This risk and the factors causing its occurrence and how to treat it have been studied in detail in the previous section.

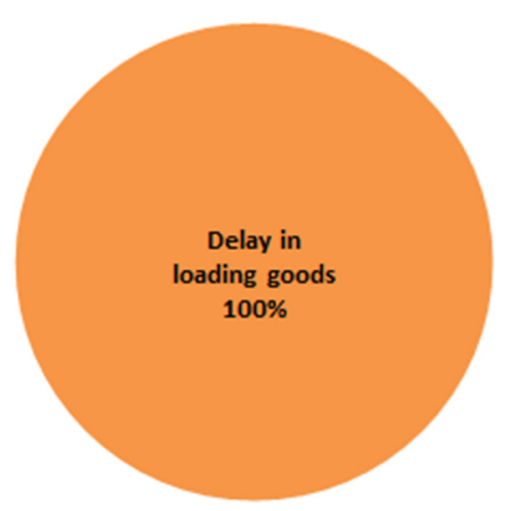

Figure 8: Representation of the matter risks. 


\subsubsection{For manpower risks}

Fig. 9 shows that $71.79 \%$ of manpower risks are psychological. Otherwise, all actions carried so far have proved to be wrong and disparate and staffs are often unable to manage their tasks without any training, information, motivation or guidance, often under the pressure of contradictory views of different responsible. Now, every organization is responsible for the occupational health and safety of its workers and others who may be affected by its activities. This responsibility includes promoting and preserving their physical and mental health [12]. These problems must be resolved to improve the work of drivers. Consequently, it is recommended to identify, upstream all the risk factors having a negative impact on the working climate and the health of the workers, even every deterioration in a worker's health situation affects his functional capacities or his work [13]. From now on, the consequences the consequences of these factors lead to functional constraints that have implications for the quality of life at work and the quality of work, even for the company's intended performance: sustainability and development [14], [15]. Despite the failure in the psychological level, only $2.56 \%$ of the risks related to physical accidents have been recorded. In our view, this is a very positive point for all of the company's employees. In terms of competence, the authors note that the majority of drivers do not exactly know the destination of customers, otherwise disruption in delivery times occurs. After analyzing the results, to mitigate this type of risk, can be used GPS. With regard to qualifications, it is very normal to be a new activity. Here, the authors propose the necessary training for new recruits to carry out this function in full compliance with the Traffic and Driver Rest Times Act (30 minutes rest after every 4 hours of driving, is obligatory).

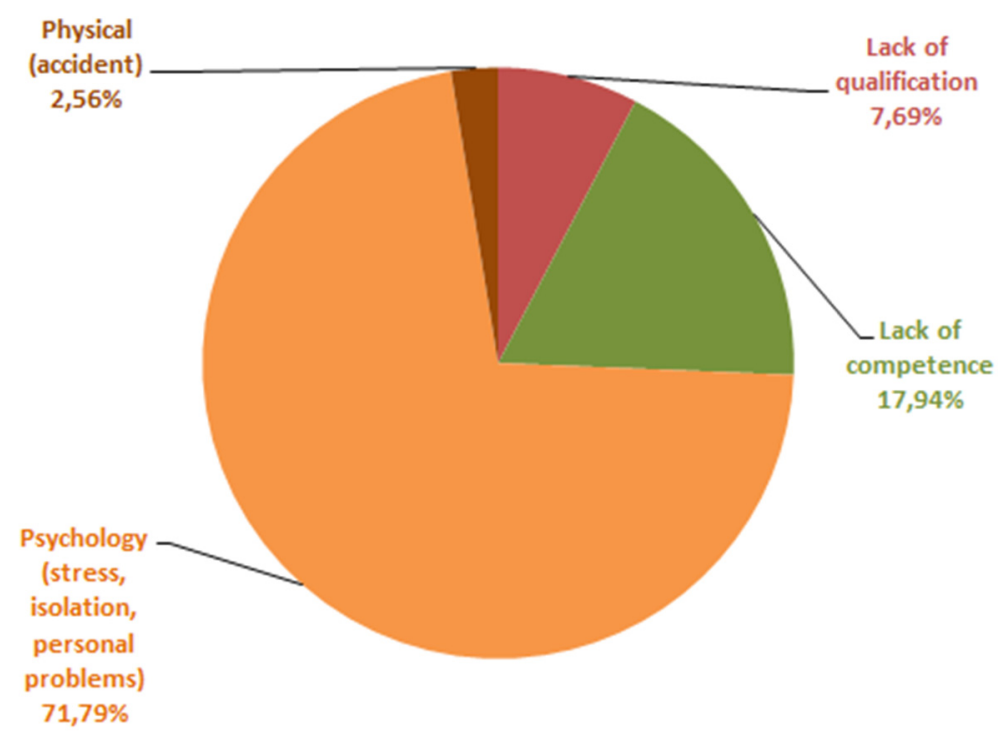

Figure 9: Representation of the manpower risks.

\section{CONCLUSION}

In conclusion, and based on the results of the analysis, it is clear that the management of the practice of the logistics organization is of paramount importance to attain a specific level of efficiency and quality of work. In addition, it can be concluded that the risks of delays in 
loading and transporting goods contribute to the emergence of a set of problems that prevent the achievement of programmed objectives. The use of the Pareto chart, allowed the authors to prioritize the actions to be carried, which are respectively the method, material risk for the problem of the delay of loading and material, matter and manpower for the delay of transport. These are the risks on which one the efforts of the manager of the organization should be concentrated without neglecting preventive measures for other risks. This work is part of a continuous improvement process. This work made it possible to categorize the problems according to its occurrence and importance and the actions to be taken according to the priorities. In addition, in order to identify and manage the risks and overcome the experience problems in an organization, a personnel cultural level must be part of the fundamental values of the actors of the work world in this field. Now, every organization is responsible for the occupational health and safety of its workers and others who may be affected by its activities. This responsibility includes the promotion and preservation of their physical and mental health. Thus, on the basis of data collected on the site, the authors propose a set of ideas that would certainly and effectively improve the management of the logistics and transport process. Subsequently, a promotion of preventive actions is also to be expected, namely:

- Promotion, information and training in occupational health and safety;

- Call on feedback. They can serve as a basis for undertaking future prevention actions;

- Develop training and welcoming programs for new employees, as well as continuing training for employees, without forgetting social dialogue (with employee representatives);

- In each action carried out, compare the results with the objectives set. To measure the effectiveness of actions, the establishment of criteria or indicators is necessary;

- Harmonize the health and safety policy with other company policies;

- Promote a multidisciplinary approach (technical, human and organizational);

- Analyze accidents and incidents, even problems by going back to the most upstream causes. 
APPENDIX

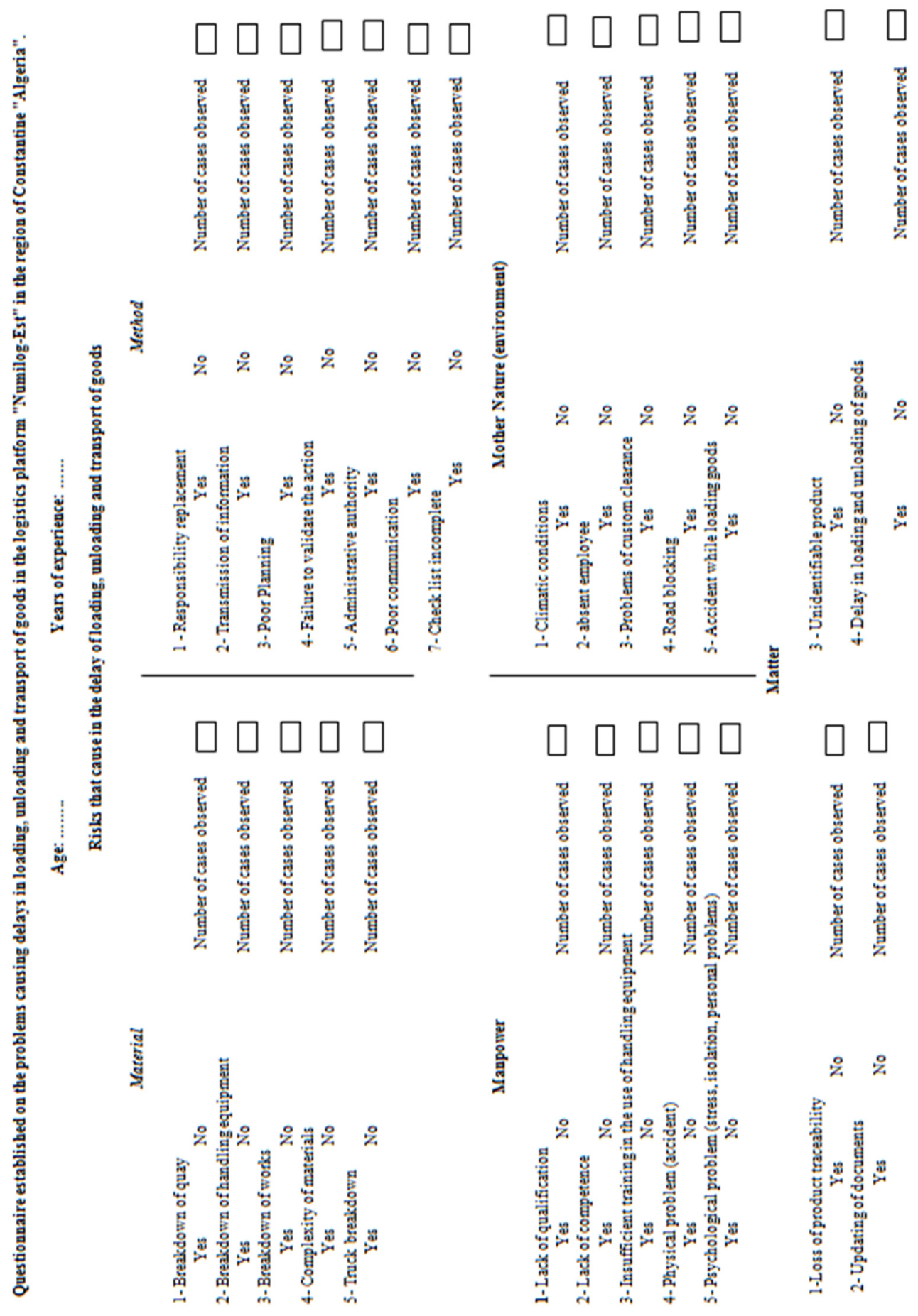

WIT Transactions on The Built Environment, Vol 206, (C) 2021 WIT Press www.witpress.com, ISSN 1743-3509 (on-line) 


\section{REFERENCES}

[1] Raimbault, N., Douet, M. \& Fremont, A., Les plateformes logistiques: Entre fluifité et fixité, Programme de recherche FLUIDE, 2010.

[2] Carrera, S., Planication et ordonnancement des plateformes logistiques. Thèse de Doctorat, Institut National Polytechnique de Lorraine, 2010.

[3] Direction général des infrastructures, Les entrepôts et les plates-formes logistique, $p$. $1,2010$.

[4] Abdel-Basset, M., Gunasekaran, M., Mohamed, M. \& Chilamkurti, N., A framework for risk assessment, management and evaluation: Economic tool for quantifying risks in supply chain. 90, pp. 489-502, 2019.

[5] Heckmann, I., Comes, T. \& Nickel, S., A critical review on supply chain risk: Definition, measure and modeling. Omega, 52, pp. 119-132, 2015.

[6] Harland, C., Brenchley, R. \& Walker, H., Risk in supply networks. Journal of Purchasing and Supply Management, 9, pp. 51-62, 2003.

[7] Yeboah, J. \& Ewur, G.D.,. The impact of WhatsApp messenger usage on students' performance in tertiary institutions in Ghana. Journal of Education and Practice, 5(6), pp. 157-164, 2014.

[8] Bolarinwa, O.A., Principles and methods of validity and reliability testing of questionnaires used in social and health science research. Nigerian Postgraduate Medical Journal, 22(4), p. 195, 2015.

[9] Chaï, R., Taleb, M., Benidir, M., Verzea, I. \& Bellaouar, A., Failure: A source of progress in maintenance and design. Physics Procedia, 55, pp. 185-191, 2014.

[10] Kharzi, R., Chaib, R. \& Akni, A., Prioritizing the actions to be undertaken in health and safety at work: Case study region of Tiaret. International Journal of Law and Management, 2020. DOI: 10.1108/IJLMA-01-2018-0009.

[11] Mounira, K., Rachid, C. \& Abdelaziz, K.A., Sensitive approach to identify black spots in urban transport, with application to cities in Algeria. Journal of Transport Problems, 16(1), 2021. DOI: 10.21307/tp-2021-017.

[12] ISO 45001:2018.

[13] Glen, P., Kenny, J.E., Yardley, L. \& Martineau, O.J., Physical work capacity in older adults: Implications for the aging worker. American Journal of Industrial Medicine, 51(8) pp: 610-625, 2008.

[14] Aboubakr, M., Contribution à l'analyse des risques et à l'amélioration de la procédure d'identification, et la hiérarchisation des mesures de contrôle, mémoire de fin d'étude, 2017.

[15] Salmi, S. \& Rachid, C., Feedback a learning tool for future organizations. World Journal of Engineering. DOI: 10.1108/WJE-12-2016-0169. 